\title{
Diabetic polyneuropathy is associated with respiratory muscle impairment in type 2 diabetes
}

\author{
H.-J. Kabitz • F. Sonntag • D. Walker • A. Schwoerer • \\ S. Walterspacher $\cdot$ S. Kaufmann $\cdot$ F. Beuschlein . \\ J. Seufert $\cdot$ W. Windisch
}

Received: 27 June 2007 / Accepted: 29 September 2007 / Published online: 22 November 2007

(C) Springer-Verlag 2007

\begin{abstract}
Aims/hypothesis Diabetes has a major negative effect on intensive care unit outcome. This has been partly attributed to impaired respiratory neuromuscular function. However, data on respiratory neuromuscular involvement in diabetes are lacking. This study therefore aimed to assess respiratory neuromuscular function related to diabetic polyneuropathy in patients with type 2 diabetes.

Methods Respiratory neuromuscular function was assessed by the use of volitional tests and twitch mouth (TwPmo) and twitch transdiaphragmatic (TwPdi) pressures during non-volitional bilateral anterior magnetic phrenic nerve stimulation in 21 male type 2 diabetic patients without pulmonary disease and in 23 healthy, well-matched controls (forced expiratory volume in $1 \mathrm{~s} 103 \pm 11$ vs $103 \pm 12 \%$ predicted; $p=0.9$ ).

Results Both volitionally assessed maximal inspiratory and expiratory mouth pressures, and sniff nasal and transdiaphragmatic pressures were comparable between diabetic patients and controls ( $p>0.1$ for all). TwPmo was reduced
\end{abstract}

H.-J. Kabitz · F. Sonntag • D. Walker · A. Schwoerer •

S. Walterspacher $\cdot$ W. Windisch $(\bowtie)$

Department of Pneumology, University Hospital Freiburg,

Killianstrasse 5,

79106 Freiburg, Germany

e-mail: wolfram.windisch@uniklinik-freiburg.de

S. Kaufmann · J. Seufert

Department of Internal Medicine II,

Division of Endocrinology-Diabetology,

University Hospital Freiburg,

Freiburg, Germany

F. Beuschlein

Department of Internal Medicine,

Division of Endocrine Research, University Hospital Munich,

Munich, Germany in diabetic patients compared with controls $(1.3 \pm 0.5$ vs $1.0 \pm$ $0.4 \mathrm{kPa} ; p=0.04)$, while TwPdi was comparable $(1.7 \pm 0.5 \mathrm{vs}$ $1.6 \pm 0.7 \mathrm{kPa} ; p=0.6)$. Following subgroup analysis, patients with no or mild polyneuropathy $(n=10)$ as assessed by neurological disability scoring had normal respiratory neuromuscular function, whereas patients with moderate or severe polyneuropathy $(n=11)$ presented with markedly impaired respiratory neuromuscular function as indicated by TwPmo $(1.3 \pm 0.4$ vs $0.8 \pm 0.3 \mathrm{kPa} ; p=0.01)$ and TwPdi $(1.9 \pm 0.6$ vs $1.1 \pm 0.4 \mathrm{kPa} ; p<0.01)$.

Conclusions/interpretation With regard to volitional tests, diabetes does not affect respiratory neuromuscular function. In contrast, the application of non-volitional phrenic nerve stimulation provides strong evidence that diabetic polyneuropathy, as simply assessed by neurological disability scoring, is associated with substantially impaired respiratory neuromuscular function in type 2 diabetic patients.

Keywords Diabetic polyneuropathy $\cdot$ Respiratory function tests $\cdot$ Respiratory muscles $\cdot$ Twitch pressure

\begin{tabular}{|c|c|}
\hline \multicolumn{2}{|c|}{ Abbreviations } \\
\hline BAMPS & $\begin{array}{l}\text { bilateral anterior magnetic phrenic nerve } \\
\text { stimulation }\end{array}$ \\
\hline$F_{\text {trig }}$ & inspiratory flow at triggering twitch pressures \\
\hline NDS & neurological disability score \\
\hline NSS & neuropathy symptom score \\
\hline$P_{0.1}$ & $\begin{array}{l}\text { mouth occlusion pressure after } 0.1 \mathrm{~s} \text { of } \\
\text { inspiration }\end{array}$ \\
\hline$P_{\text {Emax }}$ & maximal expiratory pressure \\
\hline$P_{\operatorname{Imax}}$ & $\begin{array}{l}\text { maximal inspiratory mouth pressure sustained } \\
\text { for } 1 \mathrm{~s}\end{array}$ \\
\hline$P_{\text {trig }}$ & $\begin{array}{l}\text { inspiratory pressure at triggering twitch } \\
\text { pressures }\end{array}$ \\
\hline$t_{\mathrm{i}}$ & inspiration time \\
\hline
\end{tabular}




$\begin{array}{ll}t_{\text {trig-max }} & \begin{array}{l}\text { time between trigger impulse and maximum } \\ \text { TwPmo } \\ \text { TwPdi }\end{array} \\ \text { twitch transdiaphragmatic pressure } \\ \text { TwPes } & \text { twitch oesophageal pressure } \\ \text { TwPga } & \text { twitch gastric pressure } \\ \text { TwPmo } & \text { twitch mouth pressure } \\ V_{\mathrm{T}} & \text { tidal volume }\end{array}$

\section{Introduction}

Skeletal muscle weakness is well-recognised as an important clinical manifestation of diabetic polyneuropathy [1] and is related to the severity of this condition [1-4]. In addition, diabetes has a major negative impact on intensive care unit outcome $[5,6]$, including prolonged weaning from mechanical ventilation [7]. Clinical observation also indicates that diabetes is associated with a markedly increased risk of developing respiratory failure [8]. Interestingly, a recent animal study demonstrated that diabetes induces severe impairment of diaphragmatic function, leading to a substantially decreased respiratory muscle capacity to deal with elevated workloads [8]. It has been suggested that these findings account to a large extent for the increased risk of respiratory failure in diabetic patients [8].

To date, no human studies on respiratory neuromuscular function have provided clear evidence of respiratory neuromuscular involvement in diabetic patients, since only volitional tests were used in the few previous studies [911]. However, volitional tests on respiratory neuromuscular function are highly variable due to their dependency on the participant making a truly maximal effort. Therefore, a definitive diagnosis of respiratory neuromuscular impairment in diabetic patients can only be established by the use of non-volitional tests, which are the most accurate way of assessing diaphragmatic function and currently represent the gold standard technique [12, 13]. For this reason, the present study aimed to investigate respiratory neuromuscular function in a representative group of type 2 diabetic patients with varying degrees of diabetic polyneuropathy, using both volitional and, for the first time, non-volitional tests on respiratory neuromuscular function.

\section{Methods}

Ethics The present study was performed in agreement with the ethical standards laid down in the Declaration of Helsinki. The study protocol was approved by the Institutional Review Board for Human Studies at the Albert-
Ludwigs University Freiburg, Germany. Written informed consent was obtained from all participants.

Patients and controls The current study enrolled 21 men with type 2 diabetes. Initial neurological examination was carefully performed on all participants, yielding a neurological disability score (NDS) [14, 15] and neuropathy symptom score (NSS) $[15,16]$. These scores were used to apply appropriate, and at the same time manageable, tests for diagnosing and rating diabetic polyneuropathy. The minimal criteria for diabetic polyneuropathy were adopted $[14,17]$. NDS values were used for subgroup definition of diabetic polyneuropathy, since these values have been reported to predict the development of distal muscle weakness in type 2 diabetic patients and have also been suggested to be a surrogate estimate of this complication [3]. Type 2 diabetes was diagnosed according to recent international guidelines [18]. All patients were receiving appropriate medical therapy. Ten patients were being treated with oral glucose-lowering agents and the remaining eleven patients with daily insulin injection therapy. Diabetic patients with primary lung disease, severe cardiac disease, rib cage abnormalities or musculo-skeletal disorders were excluded from the study. None of the patients had received systemic corticosteroids in the 12 months prior to the study. Twenty-three healthy men, without lung, cardiac or metabolic disease, and matched for age and BMI, served as controls. All diabetic patients and controls were naive to the experimental setting and to magnetic stimulation.

Lung function testing and biochemical markers Lung function was assessed in accordance with international guidelines [19] using body-plethysmography (MasterlabCompact; Jaeger, Hochberg, Germany). A blood sample was drawn from each participant for determination of nonenzymatic $\mathrm{HbA}_{1 \mathrm{c}}$ as a marker of metabolic control in diabetic patients.

Pressure and airflow recordings All airflow and pressure recordings were measured using a pneumotachograph and pressure transducer (ZAN 100 Flowhandy II and ZAN 400, respectively; ZAN, Oberthulba, Germany). Mouth occlusion pressure after $0.1 \mathrm{~s}$ of inspiration $\left(P_{0.1}\right)$ was assessed at functional residual capacity and used as an estimation of ventilatory drive, according to recent recommendations [13]. In addition, the pneumotachograph registered breathing frequency, tidal volume $\left(V_{\mathrm{T}}\right)$ and inspiration time $\left(t_{\mathrm{i}}\right)$ during quiet breathing. These data estimate the load imposed on the inspiratory muscles by calculating the effective inspiratory impedance as $P_{0.1} / V_{\mathrm{T}} / t_{\mathrm{i}}$ [20]. Maximal inspiratory mouth pressure sustained for $1 \mathrm{~s}\left(P_{\text {Imax }}\right)$ was measured as described previously [21]. Respiratory capac- 
ity was assessed as $P_{0.1} / P_{\text {Imax }}$ [22] to avoid underestimation of a potentially increased ventilatory drive in the presence of inspiratory muscle weakness. Maximal expiratory pressure $\left(P_{\text {Emax }}\right)$ was assessed at total lung capacity according to recent guidelines $[13,23]$. Sniff pressures were obtained at functional residual capacity as described previously [24].

During bilateral anterior magnetic phrenic nerve stimulation (BAMPS), twitch mouth (TwPmo), twitch oesophageal (TwPes) and twitch gastric (TwPga) pressures were recorded at functional residual capacity (Magstim 200²; Magstim, Whitland, UK) [25-27]. BAMPS has been consistently demonstrated to achieve supramaximality in several previous studies and this was therefore not re-tested in the present study [25, 28, 29]. A fully automated and controlled inspiratory pressure trigger was applied at $0.5 \mathrm{kPa}$ for TwPmo, as previously established [27, 30]. TwPes and TwPga were measured using a thin conventional doubleballoon catheter (ZAN, Oberthulba, Germany) in line with previous recommendations [13, 31]. Twitch transdiaphragmatic pressure (TwPdi) was calculated as the difference between TwPes and TwPga pressure-time curves by online point-to-point subtraction of TwPes from TwPga. The time between trigger impulse and maximum TwPmo $\left(t_{\text {trig-max }}\right)$ was automatically registered by the computer device. Higher $t_{\text {trig-max }}$ values indicate a pronounced delay between nerve stimulation and muscle contraction. Accordingly, this measure estimates phrenic nerve conduction time. Inspiratory pressure and inspiratory flow at triggering twitch pressures $\left(P_{\text {trig }}\right.$ and $F_{\text {trig, }}$, respectively) were recorded during triggering of twitch pressures to confirm adherence to the trigger criteria outlined previously $[27,30]$. Further details on the experimental setting for magnetic stimulation used in the present study have been published previously by our group $[27,30]$.

Study hypotheses The primary parameter of comparison in the current study was defined as the difference in respiratory neuromuscular function between diabetic patients and controls, as assessed by non-volitional TwPmo and TwPdi. Due to its superior non-volitional and non-invasive characteristics, TwPmo was designated as the primary parameter of comparison used for sample size determination. Further parameters of comparison were: (1) differences in respiratory neuromuscular function between diabetic patients with no or mild (NDS $<$ $6)$ and those with moderate or severe (NDS $\geq 6$ ) diabetic polyneuropathy following subgroup analysis; (2) differences in volitional tests on neuromuscular function between diabetic patients and controls; and (3) differences in central respiratory drive, load imposed on the inspiratory muscles and the respiratory capacity between diabetic patients and controls. Associations between parameters both of neuromuscular function and clinical and biochemical characteristics in diabetic patients were also investigated.
Statistical analysis Statistical analysis was performed using Sigma-Stat software (Version 3.1; Systat Software, Point Richmond, CA, USA). All data are presented as mean \pm SD. The null hypothesis for the primary parameter of comparison of the current study was determined as no difference in mean TwPmo values between diabetic patients and controls.

According to sample size determination (unpaired $t$ test, desired power 0.80 , two-sided type I error 0.05 ), the null hypothesis can be rejected with 21 participants in each group, based on an estimated SD of $0.33 \mathrm{kPa}$ for mean TwPmo and a difference of at least $0.30 \mathrm{kPa}$ between the two groups. Comparison between two groups was performed using the unpaired $t$ test (normally distributed data) and the Mann-Whitney rank-sum test (non-normally distributed data). For all calculations comparing more than two groups, one-way ANOVA was performed. In the event that differences were detected, an all pair-wise comparison was included using the $F$ test (Kruskal-Wallis one-way ANOVA on ranks). Pearson product moment correlation was used for correlation analysis. Linear regression analysis was performed where appropriate [32]. Statistical significance was assumed at a $p$ value of $<0.05$.

\section{Results}

Participant characteristics Demographic, clinical and lung function parameters for all groups are shown in Table 1. According to NDS, ten diabetic patients presented with no or mild diabetic polyneuropathy $(\mathrm{NDS}<6)$ and 11 patients had moderate or severe diabetic polyneuropathy (NDS $\geq 6$ ). With regard to NSS, ten patients had no or mild diabetic polyneuropathy $(\mathrm{NSS}<5)$ and 11 presented with moderate or severe diabetic polyneuropathy (NSS $\geq 5$ ). Seven patients met both criteria for moderate or severe diabetic polyneuropathy (NDS $\geq 6$ and $\mathrm{NSS} \geq 5$ ). There was no difference in age $(p=0.36)$ and $\mathrm{BMI}(p=0.30)$ when comparing the different groups following ANOVA. Lung function was normal in all participants with no differences among groups (ANOVA, $p>0.2$ in all instances). Mean duration of diabetes, mean NSS and mean $\mathrm{HbA}_{1 \mathrm{c}}$ values did not differ significantly among the diabetes subgroups with neuropathy ( $p>0.2$ in all instances).

Ventilatory characteristics and volitional tests on respiratory neuromuscular function Mean values for ventilatory drive $\left(P_{0.1}\right)$, the load imposed on the inspiratory muscles $\left(P_{0.1} / V_{\mathrm{T}} / t_{\mathrm{i}}\right)$, respiratory capacity $\left(P_{0.1} / P_{\text {Imax }}\right)$ and for the volitional tests on respiratory neuromuscular function ( $P_{\text {Imax }}, P_{\text {Emax }}$ and sniff pressures) are presented in Table 2 with footnotes indicating missing data for a particular variable where appropriate. No differences among the 
Table 1 Anthropometric, clinical and lung function characteristics in patients with type 2 diabetes and controls

\begin{tabular}{|c|c|c|c|c|}
\hline \multirow[t]{2}{*}{ Parameter } & \multirow[t]{2}{*}{ Controls } & \multicolumn{3}{|c|}{ Diabetic patients } \\
\hline & & All & $\mathrm{NDS}<6$ & $\mathrm{NDS} \geq 6$ \\
\hline$n$ & 23 & 21 & 10 & 11 \\
\hline Age (years) & $60.3 \pm 6.9$ & $63.6 \pm 7.5$ & $62.7 \pm 8.8$ & $64.4 \pm 6.5$ \\
\hline BMI $\left(\mathrm{kg} / \mathrm{m}^{2}\right)$ & $26.6 \pm 4.2$ & $28.5 \pm 4.0$ & $28.2 \pm 3.8$ & $28.8 \pm 4.3$ \\
\hline $\mathrm{FEV}_{1}(\%$ pred $)$ & $102.9 \pm 12.0$ & $103.2 \pm 10.6$ & $105.4 \pm 10.5$ & $101.3 \pm 10.8$ \\
\hline FVC (\% pred) & $109.2 \pm 13.3$ & $106.7 \pm 14.3$ & $107.2 \pm 18.4$ & $106.3 \pm 10.2$ \\
\hline $\mathrm{FEV}_{1} / \mathrm{FVC}(\%)$ & $76.8 \pm 6.3$ & $78.0 \pm 5.6$ & $80.1 \pm 5.6$ & $76.0 \pm 5.1$ \\
\hline TLC (\% pred) & $95.2 \pm 10.7$ & $97.0 \pm 11.7$ & $95.5 \pm 15.8$ & $98.3 \pm 6.8$ \\
\hline DD (months) & - & $155.2 \pm 117.8$ & $165.7 \pm 134.8$ & $145.6 \pm 105.7$ \\
\hline NSS & $1.4 \pm 2.1$ & $5.0 \pm 3.2$ & $4.2 \pm 2.9$ & $5.6 \pm 3.4$ \\
\hline $\mathrm{HbA}_{1 \mathrm{c}}(\%)$ & $5.3 \pm 0.3$ & $7.1 \pm 1.0$ & $6.9 \pm 1.0$ & $7.3 \pm 0.9$ \\
\hline
\end{tabular}

Values are expressed as means $\pm \mathrm{SD}$

$\mathrm{DD}$, duration of diabetes; $\mathrm{FEV}_{1}$, forced expiratory volume in $1 \mathrm{~s} ; \mathrm{FVC}$, forced vital capacity; \% pred, percent predicted; TLC, total lung capacity

groups could be detected according to ANOVA $(p>0.3$ in all instances). Mean values for $P_{\text {Imax }}, P_{\text {Emax }}$ and sniff pressures are illustrated in Fig. 1.

Non-volitional tests on respiratory neuromuscular function Twitch pressures and corresponding data in controls and diabetic patients are given in Table 2. Adequate TwPmo recordings were obtained from 21 of the 23 controls and from all of the 21 patients. Accordingly, suitable TwPdi recordings were available from 18 controls and 18 patients. Other participants declined either magnetic stimulation or catheter placement, or failed to produce enough acceptable twitch pressure time curves according to clearly predefined criteria $[27,30]$.
ANOVA revealed differences in TwPmo and TwPdi among the three groups. Inclusion of an all pair-wise comparison detected a reduction in mean TwPmo when controls were compared with all diabetic patients $(p=0.04)$, whereas TwPdi values were comparable ( $p=0.56$; Table 2$)$. In contrast, both TwPmo $(p=0.01)$ and TwPdi $(p<0.01)$ were significantly lower in diabetic patients with $\operatorname{NDS} \geq 6$ than in those with $\mathrm{NDS}<6$, while the latter had no impairments when compared with controls (Table 2). Mean values for twitch pressures comparing controls with all diabetic patients are illustrated in Fig. 2a. Furthermore, comparison of twitch pressures between controls and diabetic patients grouped according to $\mathrm{NDS}<6$ and $\mathrm{NDS} \geq 6$ are shown in Fig. $2 \mathrm{~b}$. Importantly, the time span between trigger impulse and

Table 2 Ventilatory characteristics, tests on respiratory neuromuscular function and corresponding data in patients with type 2 diabetes and controls

\begin{tabular}{|c|c|c|c|c|}
\hline \multirow[t]{2}{*}{ Parameter } & \multirow[t]{2}{*}{ Controls } & \multicolumn{3}{|c|}{ Diabetic patients } \\
\hline & & All & $\mathrm{NDS}<6$ & $\mathrm{NDS} \geq 6$ \\
\hline$n$ & 23 & 21 & 10 & 11 \\
\hline$P_{0.1}(\mathrm{kPa})$ & $0.21 \pm 0.08$ & $0.23 \pm 0.11$ & $0.22 \pm 0.06$ & $0.24 \pm 0.14$ \\
\hline$P_{0.1} / V_{\mathrm{T}} / t_{i}\left(\mathrm{kPa}^{-1} \mathrm{~s}^{-1}\right)$ & $0.37 \pm 0.14$ & $0.34 \pm 0.17$ & $0.31 \pm 0.13$ & $0.36 \pm 0.20$ \\
\hline$P_{0.1} / P_{\operatorname{Imax}}(\%)$ & $2.1 \pm 1.0$ & $2.3 \pm 1.1$ & $2.3 \pm 0.8$ & $2.4 \pm 1.4$ \\
\hline$P_{\text {Imax }}(\mathrm{kPa})$ & $9.0 \pm 2.0$ & $8.4 \pm 2.6$ & $8.0 \pm 2.3$ & $8.7 \pm 3.0$ \\
\hline$P_{\text {Emax }}(\mathrm{kPa})$ & $16.9 \pm 3.6^{\mathrm{a}}$ & $15.7 \pm 4.1^{\mathrm{d}}$ & $16.8 \pm 4.7$ & $14.4 \pm 3.1$ \\
\hline SnPna (kPa) & $8.7 \pm 1.7$ & $9.2 \pm 2.7^{\mathrm{b}}$ & $9.2 \pm 2.8$ & $9.1 \pm 2.8^{\mathrm{e}}$ \\
\hline SnPdi $(\mathrm{kPa})$ & $12.4 \pm 2.2^{\mathrm{b}}$ & $12.4 \pm 2.1^{\mathrm{d}}$ & $12.2 \pm 2.2$ & $12.5 \pm 2.0^{\mathrm{f}}$ \\
\hline TwPmo (kPa) & $1.30 \pm 0.47^{\mathrm{c}}$ & $1.00 \pm 0.43$ & $1.25 \pm 0.42$ & $0.78 \pm 0.32$ \\
\hline TwPdi (kPa) & $1.67 \pm 0.52^{\mathrm{a}}$ & $1.55 \pm 0.65^{\mathrm{a}}$ & $1.89 \pm 0.60$ & $1.13 \pm 0.43^{\mathrm{f}}$ \\
\hline$t_{\text {trig-max }}(\mathrm{s})$ & $0.14 \pm 0.01^{\mathrm{c}}$ & $0.14 \pm 0.02$ & $0.14 \pm 0.01$ & $0.13 \pm 0.02$ \\
\hline$P_{\text {trig }}(\mathrm{kPa})$ & $0.52 \pm 0.05^{\mathrm{c}}$ & $0.52 \pm 0.03$ & $0.51 \pm 0.02$ & $0.53 \pm 0.04$ \\
\hline$F_{\text {trig }}(\mathrm{ml} / \mathrm{s})$ & $38 \pm 26^{\mathrm{c}}$ & $28 \pm 10$ & $29 \pm 9$ & $27 \pm 11$ \\
\hline
\end{tabular}

Values are expressed as means $\pm \mathrm{SD}$

${ }^{\mathrm{a}} n=18 ;{ }^{\mathrm{b}} n=20 ;{ }^{\mathrm{c}} n=21 ;{ }^{\mathrm{d}} n=19 ;{ }^{\mathrm{e}} n=10 ;{ }^{\mathrm{f}} n=8$

$P_{0.1} / P_{\text {Imax }}$, respiratory capacity (higher values indicate reduced capacity); $P_{0.1} / V_{\mathrm{T}} / t_{\mathrm{i}}$, effective inspiratory impedance; SnPdi, sniff transdiaphragmatic pressure; SnPna, sniff nasal pressure 


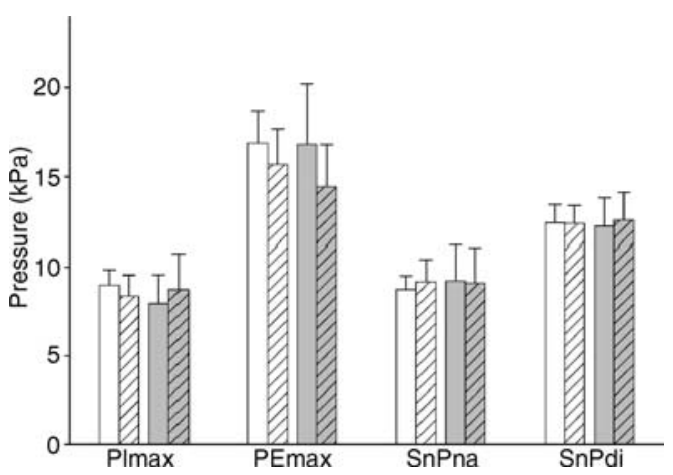

Fig. 1 Data for volitionally assessed $P_{\text {Imax }}$ and $P_{\text {Emax }}$, and sniff nasal (SnPna) and transdiaphragmatic (SnPdi) pressures in diabetic patients (all, white hatched bars; NDS $<6$, solid grey bars; NDS $\geq 6$, grey hatched bars) and controls (solid white bars). Error bars, $95 \%$ CI of the mean

pressure maximum during TwPmo assessment ( $\left.t_{\text {trig-max }}\right)$ estimating phrenic nerve conduction time was equal in all groups (ANOVA, $p>0.1$ in all instances). Adequate assessment of twitch pressures was assured in all groups, as represented by comparable values for both $P_{\text {trig }}(p=0.76)$ and $F_{\text {trig }}(p=0.24)$ following ANOVA.

\section{Correlations between respiratory neuromuscular function} and both clinical and biochemical characteristics in diabetic patients In diabetic patients, the parameters assessing respiratory neuromuscular function were not correlated to the duration of diabetes, NSS or $\mathrm{HbA}_{1 \mathrm{c}}(p>0.05$ in all instances). However, higher values for NDS were associated with lower values for TwPmo, almost reaching statistical significance $(r=-0.43 ; p=0.0516)$. In patients with NSS $\geq 5$ $(n=11)$, TwPmo $(r=-0.73 ; p=0.01)$ and TwPdi $(r=-0.87$; $p=0.005)$ were highly correlated to NDS values. Linear regression analysis for TwPdi and NDS in these patients is
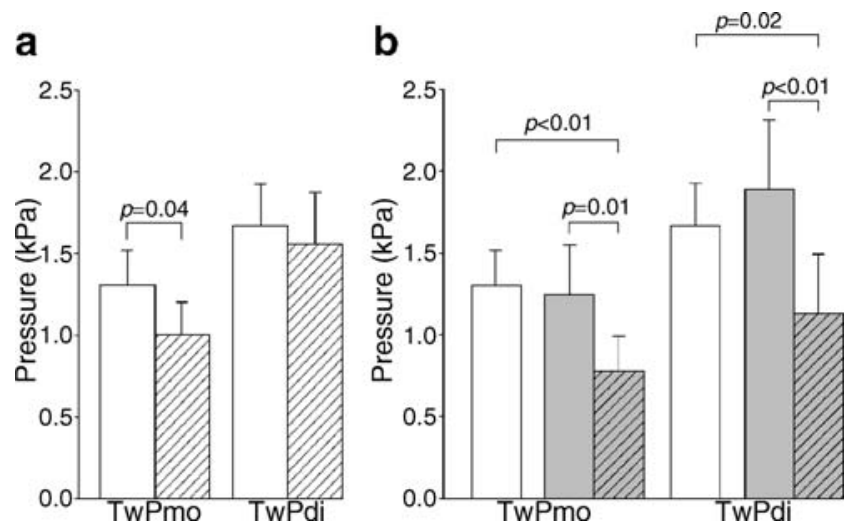

Fig. 2 a Comparison of non-volitionally assessed TwPmo and TwPdi pressures in all diabetic patients (hatched bars) and controls (solid white bars). b Mean values for TwPmo and TwPdi in controls and diabetic subgroup patients. Solid white bars, mean values for controls; solid grey bars, diabetic patients with $\mathrm{NDS}<6$; grey hatched bars, diabetic patients with NDS $\geq 6$. Error bars represent $95 \%$ CI of the mean. Significant differences are indicated on each graph illustrated in Fig. 3. Following multiple linear regression analysis adjusting for age, BMI, NSS and NDS, TwPmo in diabetic patients can only be predicted from NDS $(p<0.01)$, but not from age, BMI or NSS ( $p>0.05$ in all instances).

\section{Discussion}

The present study provides strong evidence that diabetic polyneuropathy affects respiratory neuromuscular function in patients with type 2 diabetes. The main findings are that impaired respiratory neuromuscular function, which is strongly related to diabetic polyneuropathy, occurs in type 2 diabetic patients as assessed by the primary outcome parameter TwPmo. This was particularly true for patients with symptoms of polyneuropathy in addition to neurological disability. In contrast, patients without manifest diabetic polyneuropathy had normal respiratory neuromuscular function. Co-morbidities known to be associated with respiratory muscle disorders were excluded in diabetic patients, as demonstrated by normal lung function parameters, respiratory drive, capacity and impedance. Thus, we suggest that the present findings of impaired respiratory neuromuscular function can be exclusively attributed to type 2 diabetes.

In the present study, several tests on respiratory neuromuscular function were performed in accordance with international guidelines [13], including both volitional and non-volitional tests. Interestingly, all results from volitional tests were comparable in diabetic patients and controls, indicating that global respiratory neuromuscular function is preserved in these patients. This is in line with previous studies [9] and supports the clinical observation that chronic respiratory failure caused by respiratory muscle weakness is unlikely in diabetic patients [33]. However,

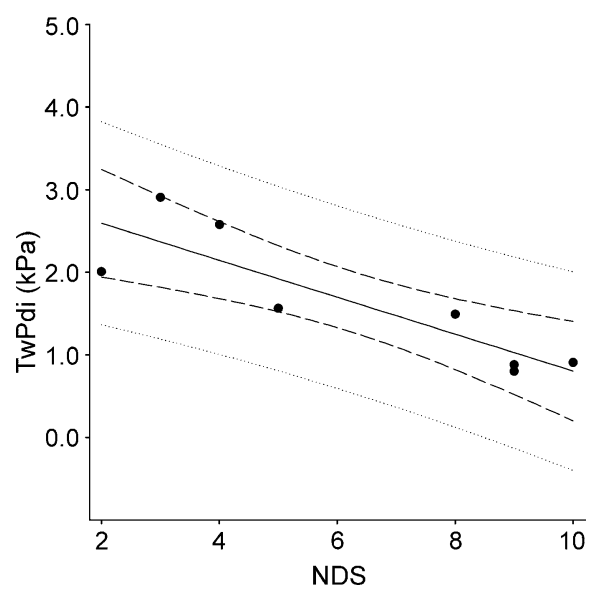

Fig. 3 Relationship between TwPdi and NDS in type 2 diabetic patients with an NSS $\geq 5$ following linear regression analysis $(n=8 ; r=-0.87$; $\left.r^{2}=0.76 ; p<0.01\right)$. The regression line between TwPdi and NDS is indicated by the solid line. Dashed line, $95 \%$ CI for the regression; dotted line, $95 \%$ CI for the population 
conflicting results of reduced sniff pressures in diabetic patients [10] and rare cases of respiratory muscle weakness representing the predominant manifestation of diabetic polyneuropathy [34-37] have also been reported.

By the use of non-volitional tests, the current study establishes the diagnosis of impaired respiratory neuromuscular function associated with diabetic polyneuropathy in type 2 diabetic patients. In contrast, respiratory neuromuscular function remains unaffected, if diabetic polyneuropathy is not present. Interestingly, TwPmo can be predicted from NDS in diabetic patients, but not from age, BMI or NSS following multiple linear regression analysis. Although not apparent during the stable state of diabetes, this finding strongly supports the observations that (1) the risk of respiratory failure is increased in diabetic patients [8] and (2) weaning from mechanical ventilation is prolonged and can be accelerated by intensive insulin therapy [7].

The pathophysiological background responsible for impaired respiratory neuromuscular function in association with diabetic polyneuropathy has not yet been conclusively investigated. However, several mechanisms have been proposed. The neuropathic process in diabetic patients is considered to be predominantly due to axonal loss rather than demyelination $[38,39]$. In line with this, phrenic nerve conduction time has been reported to be similar in diabetic patients and their corresponding controls [40]. In addition, $t_{\text {trig-max }}$ estimating phrenic nerve conduction time in the present study was comparable between controls and diabetic patients. Of note, $t_{\text {trig-max }}$ was not prolonged in the subgroup with moderate or severe diabetic polyneuropathy. For these reasons, a relevant demyelination of phrenic nerves in diabetic patients seems unlikely [40] and axonal loss of phrenic nerves is the most likely mechanism to explain reduced diaphragmatic strength. No evidence of neuromuscular transmission failure has been provided in diabetes [41]. However, myopathic processes [41, 42], changes in muscle fibre composition [43], reduced capillary density in skeletal muscles [43], abnormal action potential waveform [41, 43, 44] and the occurrence of phrenic nerve palsy associated with diabetic polyneuropathy [45] have previously been reported. In addition, autonomic neuropathy has been shown to affect respiratory function by impairing hypoxic ventilatory drive [46]. Parameters assessing respiratory neuromuscular function were not correlated with the duration of diabetes or values for $\mathrm{HbA}_{1 \mathrm{c}}$ in the current study; this supports previous findings [10].

This study has certain limitations, which need to be addressed. First, neuromuscular function assessment was focused exclusively on respiratory muscles, thus leaving potential peripheral muscle impairment unexplored. Nonetheless, numerous studies have demonstrated that peripheral muscle impairment occurs in diabetic patients and is related to the severity of diabetic polyneuropathy [1-4]. Further- more, it remains uncertain whether nerve disorder as such, neuromuscular cross-link disorders, downstream muscle dysfunction or a combination of different pathologies are responsible for impaired muscle force generation. Second, subgroup analysis for diabetic patients with no or mild polyneuropathy compared with those with moderate or severe polyneuropathy was not explicitly powered and sample size was small due to the demanding study design. Therefore, the estimation of differences between the two groups could be misjudged, although this seems unlikely. Studies including larger sample sizes are needed to further investigate associations between diabetic polyneuropathy and respiratory neuromuscular function in diabetic patients. Finally, several tests for diagnosing and rating polyneuropathy have been introduced in clinical practice [47]. It cannot be excluded with certainty that the application of tests other than the NSS and NDS used in the current study could have led to different ratings. However, currently no gold standard exists for diagnosing diabetic polyneuropathy [48] and the tests applied in this study meet the required criteria as outlined previously $[47,48]$.

In conclusion, volitionally assessed respiratory neuromuscular function is not affected in type 2 diabetic patients. In contrast, the current study provides first evidence that diabetic polyneuropathy, as assessed by simple clinical examination, is associated with substantially impaired respiratory neuromuscular function in type 2 diabetic patients, when nonvolitional gold-standard phrenic nerve stimulation is applied.

Acknowledgements All participants are acknowledged for the effort they devoted to this study. R. Merklein (ZAN, Oberthulba, Germany) is gratefully acknowledged for technical advice, S. Rubenbauer for statistical consulting, S. Dieni for proofreading the manuscript, and the medical assistants from the Diabetes Outpatient Center, University Hospital Freiburg for their help with data collection.

Duality of interest The authors declare that there is no duality of interest associated with this manuscript.

\section{References}

1. Andersen H, Nielsen S, Mogensen CE, Jakobsen J (2004) Muscle strength in type 2 diabetes. Diabetes 53:1543-1548

2. Andersen H, Poulsen PL, Mogensen CE, Jakobsen J (1996) Isokinetic muscle strength in long-term IDDM patients in relation to diabetic complications. Diabetes 45:440-445

3. Andreassen CS, Jakobsen J, Andersen H (2006) Muscle weakness: a progressive late complication in diabetic distal symmetric polyneuropathy. Diabetes 55:806-812

4. Park SW, Goodpaster BH, Strotmeyer ES et al (2006) Decreased muscle strength and quality in older adults with type 2 diabetes: the health, aging, and body composition study. Diabetes 55:1813-1818

5. Langdon CD, Shriver RL (2004) Clinical issues in the care of critically ill diabetic patients. Crit Care Nurs Q 27:162-171

6. Rady MY, Johnson DJ, Patel BM, Larson JS, Helmers RA (2005) Influence of individual characteristics on outcome of glycemic control in intensive care unit patients with or without diabetes mellitus. Mayo Clin Proc 80:1558-1567 
7. Van den Berghe G, Wilmer A, Hermans G et al (2006) Intensive insulin therapy in the medical ICU. N Engl J Med 354:449-461

8. Callahan L, Supinski G, Augusta G (2006) Diabetes markedly reduces respiratory pump capacity. Proc Am Thorac Soc 3:A259 (abstract)

9. Heimer D, Brami J, Lieberman D, Bark H (1990) Respiratory muscle performance in patients with type 1 diabetes. Diabet Med 7:434-437

10. Wanke T, Formanek D, Auinger M, Popp W, Zwick H, Irsigler K (1991) Inspiratory muscle performance and pulmonary function changes in insulin-dependent diabetes mellitus. Am Rev Respir Dis 143:97-100

11. Mancini M, Filippelli M, Seghieri G et al (1999) Respiratory muscle function and hypoxic ventilatory control in patients with type I diabetes. Chest 115:1553-1562

12. Polkey MI, Green M, Moxham J (1995) Measurement of respiratory muscle strength. Thorax 50:1131-1135

13. No authors listed (2002) ATS/ERS statement on respiratory muscle testing. Am J Respir Crit Care Med 166:518-624

14. Dyck PJ, Kratz KM, Lehman KA et al (1991) The Rochester Diabetic Neuropathy Study: design, criteria for types of neuropathy, selection bias, and reproducibility of neuropathic tests. Neurology 41:799-807

15. Young MJ, Boulton AJ, MacLeod AF, Williams DR, Sonksen PH (1993) A multicentre study of the prevalence of diabetic peripheral neuropathy in the United Kingdom hospital clinic population. Diabetologia 36:150-154

16. Dyck PJ, Sherman WR, Hallcher LM et al (1980) Human diabetic endoneurial sorbitol, fructose, and myo-inositol related to sural nerve morphometry. Ann Neurol 8:590-596

17. Walters DP, Gatling W, Mullee MA, Hill RD (1992) The prevalence of diabetic distal sensory neuropathy in an English community. Diabet Med 9:349-353

18. No authors listed (1999) Definition, diagnosis and classification of diabetes mellitus and its complications. WHO: Report of a WHO consultation. Part I: Diagnosis and classification of diabetes mellitus. WHO, Geneva

19. Quanjer PH, Tammeling GJ, Cotes JE, Pedersen OF, Peslin R, Yernault JC (1993) Lung volumes and forced ventilatory flows. Report Working Party Standardization of Lung Function Tests, European Community for Steel and Coal. Official Statement of the European Respiratory Society. Eur Respir J Suppl 16:5-40

20. Whitelaw WA, Derenne JP, Milic-Emili J (1975) Occlusion pressure as a measure of respiratory center output in conscious man. Respir Physiol 23:181-199

21. Windisch W, Hennings E, Sorichter S, Hamm H, Criee CP (2004) Peak or plateau maximal inspiratory mouth pressure: which is best? Eur Respir J 23:708-713

22. Fernandez R, Cabrera J, Calaf N, Benito S (1990) P 0.1/PIMax: an index for assessing respiratory capacity in acute respiratory failure. Intensive Care Med 16:175-179

23. Leech JA, Ghezzo H, Stevens D, Becklake MR (1983) Respiratory pressures and function in young adults. Am Rev Respir Dis 128:17-23

24. Heritier F, Rahm F, Pasche P, Fitting JW (1994) Sniff nasal inspiratory pressure. A noninvasive assessment of inspiratory muscle strength. Am J Respir Crit Care Med 150:1678-1683

25. Mills GH, Kyroussis D, Hamnegard CH, Polkey MI, Green M, Moxham J (1996) Bilateral magnetic stimulation of the phrenic nerves from an anterolateral approach. Am J Respir Crit Care Med 154:1099-1105

26. Polkey MI, Moxham J (2001) Clinical aspects of respiratory muscle dysfunction in the critically ill. Chest 119:926-939
27. Kabitz HJ, Walker D, Walterspacher S, Windisch W (2007) Controlled twitch mouth pressure reliably predicts twitch esophageal pressure. Respir Physiol Neurobiol 156:276-282

28. Man WDC, Luo YM, Mustfa N et al (2002) Postprandial effects on twitch transdiaphragmatic pressure. Eur Respir J 20:577-580

29. Mador MJ, Khan S, Kufel TJ (2002) Bilateral anterolateral magnetic stimulation of the phrenic nerves can detect diaphragmatic fatigue. Chest 121:452-458

30. Windisch W, Kabitz HJ, Sorichter S (2005) Influence of different trigger techniques on twitch mouth pressure during bilateral anterior magnetic phrenic nerve stimulation. Chest 128:190-195

31. Milic-Emili J, Mead J, Turner JM, Glauser EM (1964) Improved technique for estimating pleural pressure from esophageal balloons. J Appl Physiol 19:207-211

32. Bland JM, Altman DJ (1986) Regression analysis. Lancet 1: 908-909

33. Hughes RA, Bihari D (1993) Acute neuromuscular respiratory paralysis. J Neurol Neurosurg Psychiatry 56:334-343

34. Said G, Goulon-Goeau C, Slama G, Tchobroutsky G (1992) Severe early-onset polyneuropathy in insulin-dependent diabetes mellitus. A clinical and pathological study. N Engl J Med 326:1257-1263

35. Brannagan TH, Promisloff RA, McCluskey LF, Mitz KA (1999) Proximal diabetic neuropathy presenting with respiratory weakness. J Neurol Neurosurg Psychiatry 67:539-541

36. Tang EW, Jardine DL, Rodins K, Evans J (2003) Respiratory failure secondary to diabetic neuropathy affecting the phrenic nerve. Diabet Med 20:599-601

37. Haubenberger D, Rinner W, Auff E, Fertl E (2004) Global respiratory insufficiency due to proximal diabetic neuropathy. $\mathrm{J}$ Neurol 251:1536-1537

38. Krarup C (2003) An update on electrophysiological studies in neuropathy. Curr Opin Neurol 16:603-612

39. Dyck PJ, Kratz KM, Karnes JL et al (1993) The prevalence by staged severity of various types of diabetic neuropathy, retinopathy, and nephropathy in a population-based cohort: the Rochester Diabetic Neuropathy Study. Neurology 43:817-824

40. Wanke T, Paternostro-Sluga T, Grisold W et al (1992) Phrenic nerve function in type 1 diabetic patients with diaphragm weakness and peripheral neuropathy. Respiration 59:233-237

41. Grossie J (1982) Contractile and electrical characteristics of extensor muscle from alloxan-diabetic rats. An in vitro study. Diabetes 31:194-202

42. McGuire M, MacDermott M (1998) The influence of streptozotocininduced diabetes and the antihyperglycaemic agent metformin on the contractile characteristics and the membrane potential of the rat diaphragm. Exp Physiol 83:481-487

43. Marin P, Andersson B, Krotkiewski M, Bjorntorp P (1994) Muscle fiber composition and capillary density in women and men with NIDDM. Diabetes Care 17:382-386

44. van Lunteren E, Moyer M (2003) Streptozotocin-diabetes alters action potentials in rat diaphragm. Respir Physiol Neurobiol 135:9-16

45. Rice AL, Ullal J, Vinik AI (2007) Reversal of phrenic nerve palsy with topiramate. J Diabetes Complications 21:63-67

46. Sobotka PA, Liss HP, Vinik AI (1986) Impaired hypoxic ventilatory drive in diabetic patients with autonomic neuropathy. J Clin Endocrinol Metab 62:658-663

47. Meijer JW, Smit AJ, Lefrandt JD et al (2005) Back to basics in diagnosing diabetic polyneuropathy with the tuning fork! Diabetes Care 28:2201-2205

48. Meijer JW, van Sonderen E, Blaauwwiekel EE et al (2000) Diabetic neuropathy examination: a hierarchical scoring system to diagnose distal polyneuropathy in diabetes. Diabetes Care 23:750-753 